\title{
Toward Urban Planetary Health Solutions to Climate Change and Other Modern Crises
}

\author{
Jonathan A. Patz • José G. Siri
}

Published online: 14 May 2021

(C) The New York Academy of Medicine 2021

We are faced today with multiple, overlapping, globalscale crises, from biodiversity loss to climate change to the ongoing COVID-19 pandemic. There is no longer any credible doubt, for example, that our collective emissions drive global warming, and evidence suggests that degraded landscapes and ecosystems are at least partly to blame for the emergence of the new coronavirus [1], as they are for viral spillover more generally. The emerging field of planetary health is a framework for understanding these interconnections and identifying solutions to the complex challenges confronting our civilization.

Near the turn of this 21 st century, for the first time in human existence, urban dwellers became a majority of the human population. Cities, and the demand for urban goods and services, account for most environmental impacts, while city dwellers also face disproportionate risks from global environmental change-including climate change. Considering the steep trajectory of projected urbanization, cities are certain to remain both the site for the most serious global environmental health impacts and the source for the most needed solutions.

This is the rationale behind this special issue of the Journal of Urban Health, dedicated to Climate Change

\footnotetext{
J. A. Patz $(\bowtie)$

Global Health Institute, University of Wisconsin, Madison, WI, USA

e-mail: patz@wisc.edu

J. G. Siri

Our Planet Our Health Programme at Wellcome Trust, London, England, UK
}

and Planetary Health. In it, we explore relationships between urban health and a range of sectors critical to climate change solutions, including transport, housing, green space, and urban planning, as well as methodological approaches to generate more effective action. One thread that unifies the research gathered here is the destructive impacts of inequity, which takes its place alongside other global crises as a critical challenge to health; without interventions that address and redress inequity, planetary health solutions cannot be lasting.

One key to urban health and climate solutions is transportation planning. The transportation sector accounts for about $14 \%$ of greenhouse gas emissions, and transport systems deeply influence physical and mental health and safety for most urban dwellers. A shift to active travel (i.e., walking, cycling and mass transit), for instance, would reduce emissions while promoting physical fitness. Worldwide, sedentary lifestyles cause an estimated 3.9 million deaths every year [2]. Air pollution from transportation causes an estimated $11.4 \%$ of global deaths related to ambient $\mathrm{PM}_{2.5}$ and $\mathrm{O}_{3}$, and an estimated $\$ 1$ trillion per year is spent on adverse health effects related to transport emissions [3]. Meanwhile, there were 1.35 million road traffic fatalities globally in 2016 [4]. We need sustainable, evidencebased transport options in our cities that are easy, universally accessible, and safe.

In this issue, Raifman et al. [5] examine the Transportation Climate Initiative (TCI), a partnership of 12 US states and the District of Columbia aimed at implementing a cap-and-invest program to reduce transportation-related emissions across the Northeast 
and Mid-Atlantic regions. The authors find that even a small investment in active mobility would lead to hundreds fewer deaths per year, with monetized benefits in the billions of dollars - substantially exceeding the direct costs of investment. Sun et al. [6] examine transport in the context of the relationship between urban form, road traffic, and lung cancer incidence in high-density downtown Shanghai, China. They find positive correlations between a variety of infrastructure, housing, and transport design factors and lung cancer, but a negative association with population density, perhaps associated with reduced reliance on cars and travel distances in well-serviced, dense neighborhoods. They suggest a need for further longitudinal studies to account for self-selection effects.

Wang et al. [7] also examine relationships between urban form and health, in this case in the context of urban heat in Maricopa County, AZ, home to the major city of Phoenix. Earlier work [8] suggested that by midcentury this region may experience six months per year of temperatures above $95^{\circ} \mathrm{F}\left(35^{\circ} \mathrm{C}\right)$. Globally, urban populations exposed to average summertime highs in this range are projected to increase by $800 \%$ to 1.6 billion [9]. The authors find considerable spatial heterogeneity in the relationships between demographic, socioeconomic, housing, and environmental factors and heat-related morbidity. Their analysis suggests avenues for improving prediction and risk management for vulnerable populations across the region.

Designing for equity is paramount to success in grappling with the climate and ecological crises that threaten our health in cities. Several articles in this issue highlight challenges and opportunities for urban health equity. Two focus on Greater London, with potential lessons for other major cities: Symonds et al. [10] examine relationships between home energy efficiency, energy consumption, and self-reported health. Their analysis suggests that home energy efficiency provides cobenefits for occupants' health, provided that adequate air exchange is maintained, and that the least well-off may benefit most from home energy efficiency programs. Shoari et al. [11] quantify access to open and green space at schools, finding that nearly a third of pupils attend schools with less than the minimum recommended amount of open space; access to green space is even rarer. They examine associations with socioeconomic and geographic variables and offer recommendations for maintaining or expanding students' contact with green space, which is associated with broad physical and mental health benefits. Another article by Kidd et al. [12] features a systematic review of the health and social implications of global climate change for the homeless, a particularly marginalized group in most societies. The authors find that climate change will influence the prevalence of homelessness while exacerbating specific vulnerabilities of homeless populations - such as chronic disease and environmental exposures. It will also impose new challenges for health services and social systems. A framework is proposed to inform future research and service design in this understudied group.

Complexity is a hallmark of urban planetary health issues, with outcomes determined by the interactions of multiple ecological, physical, and social systems, often removed from the traditional institutions and interventions of public health. Securing healthy, sustainable cities will require new methods and modes of working to engage with this complexity $[13,14]$. Here, Audia et al. [15] present a framework for the co-production of knowledge between researchers and societal partners. In the context of an urban health equity project in Accra, Ghana, they highlight how the partial, circumscribed nature of co-production and its embeddedness in local contexts challenges traditional conceptions and practices. They lay out a novel, structured process for coproduction based on flexible, recursive components. Subsequently, paired papers describe insights from the UPSTREAM study, which sought to value the health cost-benefits associated with the quality of urban environments and to characterize barriers and opportunities for creating healthy urban environments in the UK, e.g., in relation to economic valuation, land tenure, and other upstream issues. Scally et al. [16] first describe the application of "elite interviewing" methods to engage senior-level urban planning decision-makers. Black et al. [17] then summarize results from these interviews, highlighting that, while many senior-level planners were well aware of human health linkages with urban planning, health is not factored adequately into the urban planning process, and planners welcomed more input from health experts.

COVID-19 has unveiled stark inequities within and between societies that intersect with key issues in planetary health. In the US, for example, the pandemic has claimed nearly four times as many Black and three times as many Hispanic lives as White. Often, differences in exposure and vulnerability are compounded by existing environmental inequalities. Earlier work [18] has 
estimated that a $1 \mathrm{ug} / \mathrm{m}^{3}$ increase in fine particulate matter $\left(\mathrm{PM}_{2.5}\right)$ leads to an eight percent rise in the risk of dying from COVID-19-globally, those most exposed to air pollution are disproportionately from low income and marginalized populations.

In the aftermath of COVID-19, resounding calls to "Build Back Better" recognize that we must seek to leverage the lessons we have learned about resilience, governance, cascading risks, and the intimate linkages between environment and health to imagine and create a better future. In this issue, Kephart et al. [19] compare air quality levels in four major Latin American cities during the initial phase of lockdown with those before the pandemic, estimating the impact on adult mortality if COVID-19-related PM2.5 reductions were maintained over the long term. This hopeful vision sees adult mortality drop by as much as $41 \%$ (in Lima, Peru), hinting at tremendous potential for a region where 145,000 annual deaths are caused by ambient air pollution. These results are consistent with other regional studies that have estimated rapid drops in mortality due to COVID-19 response: for example, in China, improved air quality over a two-month period was estimated to have saved 24,200 lives [20]. Air pollution is just one point of contact between COVID-19 and planetary health. Here, Milner et al. [21] outline the implications of the pandemic for action to tackle climate change and promote health in cities. In so doing, they explore the vulnerability of society to unexpected risks, the need for evidencebased policy and effective science communication, the inequitable distribution of COVID-19 impacts, and the possibility of large-scale action at pace.

Two commentaries round out this special issue. The first, from Hérick de Sa et al. [22], broadly highlights the World Health Organization's mission at the intersection of urban and planetary health, including providing leadership, strengthening the knowledge base, and offering technical support and coordination for local governments, with an emphasis on multi-sectoral action. The second, from Pineo et al. [23], gathers insights from research projects funded by the Wellcome Trust's Our Planet, Our Health program on the methodological challenges inherent in large-scale urban planetary health research, as developed in a participatory workshop at the 2019 International Conference on Urban Health.

As urban populations and resource demands grow steadily, it becomes ever easier to trace their impacts on the converging crises we face-climate change, environmental degradation, widespread and growing inequity. To resolve these challenges, we will need truly local-to-global responses. Yet, it is within cities themselves - with their proliferation of interconnected people, institutions, and ideas - that strategic, lasting solutions can and must emerge. Central to these solutions will be a systems-based approach to planetary health that recognizes the profound interconnections between our collective decisions, the state of our earthly home, and the tenor of our common future.

Acknowledgements Support for JAP comes from the John P. Holton Chair of Health and the Environment at the University of Wisconsin-Madison. Support for JGS comes from the Wellcome Trust.

\section{References}

1. Plowright R, Reaser J, Locke H, Woodley SJ, Patz JA, Becker D, et al. A call to action: understanding land useinduced zoonotic spillover to protect environmental, animal, and human health [Internet]. EcoEvoRxiv; 2020. Available from: https://ecoevorxiv.org/cru9w/. Accessed March 11, 2021.

2. Strain T, Brage S, Sharp SJ, Richards J, Tainio M, Ding D, et al. Use of the prevented fraction for the population to determine deaths averted by existing prevalence of physical activity: a descriptive study. The Lancet Global Health. Elsevier. 2020;8:e920-30.

3. Anenberg SC, Miller J, Henze DK, Minjares R, Achakulwisut P. The global burden of transportation tailpipe emissions on air pollution-related mortality in 2010 and 2015. Environ Res Lett. IOP Publishing. 2019;14:094012.

4. WHO. Global status report on road safety 2018 [Internet]. Geneva, Switzerland: World Health Organization; 2018. Available from: https://www.who.int/publications/ i/item/9789241565684. Accessed 8 Mar 2021.

5. Raifman M, Lambert KF, Levy JI, Kinney PL. Mortality implications of increased active mobility for a proposed regional transportation emission cap-and-invest program. J Urban Health [Internet]. 2021; Available from: https://doi. org/10.1007/s11524-020-00510-1. Accessed March 11, 2021.

6. Sun W, Bao P, Zhao X, Tang J, Wang L. Road traffic and urban form factors correlated with the incidence of lung cancer in high-density areas: an ecological study in downtown Shanghai, China. J Urban Health [Internet]. 2021; Available from: https://doi.org/10.1007/s11524-021-00529-y. Accessed March 11, 2021.

7. Wang C, Solís P, Villa L, Khare N, Wentz EA, Gettel A. Spatial modeling and analysis of heat-related morbidity in Maricopa County, Arizona. Journal of Urban Health. 2021;

8. Xu C, Kohler TA, Lenton TM, Svenning J-C, Scheffer M. Future of the human climate niche. PNAS. National Academy of Sciences. 2020;117:11350-5. 
9. UCCRN. Impact 2050: the future of cities under climate change: Urban Climate Change Research Network. New York, NY. 2018.

10. Symonds P, Verschoor N, Chalabi Z, Taylor J, Davies M. Home energy efficiency and subjective health in Greater London. Journal of Urban Health. 2021;

11. Shoari N, Ezzati M, Doyle YG, Wolfe I, Brauer M, Bennett $\mathrm{J}$, et al. Nowhere to play: available open and green space in Greater London schools. Journal of Urban Health. 2021;

12. Kidd SA, Greco S, McKenzie K. Global Climate implications for homelessness: a scoping review. J Urban Health [Internet]. 2020; Available from: https://doi.org/10.1007 /s11524-020-00483-1. Accessed March 11, 2021.

13. Siri JG. Sustainable, healthy cities: making the most of the urban transition. Public Health Reviews. 2016;37:22.

14. Bai X, Surveyer A, Elmqvist T, Gatzweiler FW, Güneralp B, Parnell S, et al. Defining and advancing a systems approach for sustainable cities. Current Opinion in Environmental Sustainability. 2016;23:69-78.

15. Audia C, Berkhout F, Owusu G, Quayyum Z, AgyeiMensah S. Loops and building blocks: a knowledge coproduction framework for equitable urban health. Journal of Urban Health. 2021;

16. Scally G, Black D, Pilkington P, Williams B, Ige J, Prestwood E. The application of 'elite interviewing' methodology in transdisciplinary research: a record of process and lessons learned during a three-year pilot in urban planetary health research. Journal of Urban Health. 2021;

17. Black D, Pilkington P, Williams B, Ige J, Prestwood E, Hunt A, et al. Overcoming systemic barriers preventing healthy urban development in the UK: main findings from interviewing senior decision-makers during a three-year planetary health pilot. Journal of Urban Health. 2021;

18. Wu X, Nethery RC, Sabath MB, Braun D, Dominici F. Air pollution and COVID-19 mortality in the United States: strengths and limitations of an ecological regression analysis. Science Advances. American Association for the Advancement of Science. 2020;6:eabd4049.

19. Kephart JL, Avila-Palencia I, Bilal U, Gouveia N, Caiaffa WT, Diez Roux AV. COVID-19, Ambient Air Pollution, and Environmental Health Inequities in Latin American Cities. J Urban Health [Internet]. 2021; Available from: https://doi.org/10.1007/s11524-020-00509-8. Accessed March 11, 2021.

20. Giani P, Castruccio S, Anav A, Howard D, Hu W, Crippa P. Short-term and long-term health impacts of air pollution reductions from COVID-19 lockdowns in China and Europe: a modelling study. The Lancet Planetary Health. Elsevier. 2020;4:e474-82.

21. Milner J, Davies M, Haines A, Huxley R, Michie S, Robertson L, et al. Emerging from COVID-19: lessons for action on climate change and health in cities. J Urban Health [Internet]. 2021; Available from: https://doi.org/10.1007 /s11524-020-00501-2. Accessed March 11, 2021.

22. Hérick de Sa T, Ludolph R, Hinsch M, Roebbel N. Health at the heart of urban and territorial planning - the WHO's multi-sectoral leadership for human and planetary health. Journal of Urban Health. 2021;

23. Pineo H, Audia C, Black D, French M, Gemmell E, Lovasi GS, et al. Building a methodological foundation for impactful urban planetary health science. J Urban Health [Internet]. 2020; Available from: https://doi.org/10.1007/s11524-02000463-5. Accessed March 11, 2021.

Publisher's Note Springer Nature remains neutral with regard to jurisdictional claims in published maps and institutional affiliations. 